\title{
Depictions of females and males in Mozambican and Victorian (Australia) primary mathematics textbooks
}

\author{
Adelino Evaristo Murimo and Helen Forgasz \\ Monash University, Australia \\ Email: mailto:ademurimo@yahoo.com.au and helen.forgasz@education.monash.edu.au
}

\begin{abstract}
The depiction of females and males in Mozambican Primary Mathematics textbooks for grades 6 and 7 were examined, and comparisons made with Victorian (Australia) textbooks for years 5 and 6. It was found that mathematics learning was portrayed as a male domain in the Mozambican textbooks, reflecting what used to be the case with Australian texts of the 1970s, although there are some differences between the two countries that may be culturally based. The Victorian textbooks depicted mathematics learning as a domain for all children, and in the majority of categories examined, females and males were distributed fairly evenly. Compared to earlier reported findings, there was a general improvement in the portrayal of females in Victorian textbooks.
\end{abstract}

\section{Introduction and background to study}

In Mozambique, activities aimed at eliminating gender disparities in education became popular in the 1990s through UNICEF intervention projects soon after the country ratified the Declaration on Education for All (EFA) (Bernard \& Cabral, 2002). Since then, there have been three main objectives forming the focus of UNICEF projects: to increase the enrolment rates of girls in the early school grades, to ensure that enrolled girls do not drop-out, and to ensure that girls do not fail the grade they are attending (Guz, 2000; Bernard \& Cabral, 2002). However, despite the efforts of the government and non-governmental organisations, a national evaluation report carried out by UNICEF indicated that although the school participation of girls and boys in grades 1 to 5 tended to be similar, there were fewer girls than boys in grades 6 and 7 , and there were differences across the provinces (Guz, 2000). Moreover, fewer than 40\% of Mozambican children complete primary education and there is a gender gap in completion rate of over $20 \%$, with fewer girls completing primary schooling than boys. UNICEF therefore questioned whether Mozambique was going to achieve one of the key purposes of the United Nations Millennium Development Goals (MDG), the completion of primary education for all by 2015 .

To date, official accounts of the gender disparities in Mozambican schools have been attributed to poverty in the majority of families, and to schools which are unsafe for girls because of harassment by adult males (Guz, 2000; Bernard \& Cabral, 2002; UNICEF, 2006). It has been claimed that some parents tend to keep their daughters at home so that they can help with farming, fetching water, and even income generation. The long walking distances to schools and the lack of piped water and separate facilities in schools have also been identified as causes for gender disparities in education. As a consequence, the affirmative actions of government and nongovernmental organisations to promote girls' education have concentrated mostly on subsidiary issues, such as money given to girls to support them at school. Little has been done to look into the curriculum, that is, to question to what extent the curriculum is 'girl-friendly'.

In Mozambique, gender equity in education has been discussed mainly in terms of equal participation of girls and boys in the classroom (Guz, 2000; Bernard \& Cabral, 2002; UNICEF, 2006). Although this is an important starting point, one of the other critical dimensions of gender equity in education is equal educational outcomes (Fennema, 1990). Equal educational outcomes demand that girls and boys must both experience good quality teaching. In fact, Fennema (ibid.) linked the problem of gender equity in mathematics education to certain teaching approaches valued by teachers:

Achieving equivalent outcomes in mathematics education for males and females may require that teachers actually treat the sexes differently. It could be that the most effective teaching for males is different from that of females. For example, there is some evidence that classes organised to provide competition result in somewhat better learning for males, while classrooms that encourage cooperation 

textbooks

are better for females...[italics added]

(Fennema, 1990: 5-6).

Fennema (ibid.) also argued that there were reasons other than economic ones leading to gender disparities in mathematics learning. She pointed out that females contributed to mathematics knowledge in the past, but that societal attitudes inhibited such contributions. She suggested that girls should be given opportunities to experience and to contribute to mathematics knowledge just as boys do.

It was Fennema's (1990) arguments that motivated the analysis of gender differences in Mozambican textbooks and the comparison with Victorian (Australia) textbooks that are reported in this article. The inclusion of textbooks from Victoria was purposeful because efforts to bring about gender equity in textbooks in Australia date back to the 1970s (Australian College of Education, 1977; Clarkson, 1993; Forgasz, 1996; McKimmie, 2002). Also, gender issues have been discussed in teacher education programs in Australia and there is general acceptance that females and minority groups should be treated fairly in school materials (Clarkson, 1993).

The study reported here sought to answer the following questions:

1) Are the photos and drawings illustrating females and males distributed with the same frequency in the mathematics textbooks?

2) Among the photos and drawings illustrating people, how often do females and males appear together?

3) Do females and males share equal active (physical) and passive (non-physical) roles? In their active and passive roles, are females and males equally mathematically cognitively engaged?

4) Are females and males mentioned with the same frequency in mathematical problems?

5) How are selected mathematics educational values (accessibility and 'specialism' - defined on page 89) evident in the textbooks? Are there differences along gender lines?

6) What are the important differences in the findings in the textbooks of Mozambique and Victoria?

For a better understanding of the differences and similarities in the data obtained in this study, an overview of the Mozambican system of education is described briefly in the section that follows.

\section{Mozambican system of education}

Due to important differences between Mozambique and Victoria in terms of language used for school instruction, curriculum and culture, the Mozambican system of education is described in order to assist in understanding the findings from this study.

The language of instruction in Mozambique is Portuguese, a legacy of over 500 years of western and colonial experience. As in many other African countries, the Mathematics curriculum in Mozambique is a curriculum transplantation, that is, the content reflects western values (Gerdes, 1988). Despite the vast numbers of people entering schools soon after independence in many former western colonies, including Mozambique, the Mathematics curriculum retained its western roots. The Mozambican Ministry of Education and Culture is currently attempting to restructure the curriculum by considering issues such as native languages, gender and cultural values (Guz, 2000).

The formal education system used in Mozambique is a ' $5+2+3+2$ ' model which means children study five years at Lower Primary level, two years at Upper Primary, three years at Lower Secondary, and two years at Upper Secondary level. They graduate from one level to the next level by sitting for national examinations.

Portuguese and Mathematics are compulsory subjects for all students up to Lower Secondary level. In order to move from one level to the next, students must be competent in both subjects as these are considered the core subjects in further studies (Ministério de Educação e Cultura, 2003). At the Upper Secondary Education level, Mathematics is optional.

\section{Mathematics teaching in Mozambican schools}

In a typical Mozambican Primary School Mathematics classroom, the furniture is organised in rows of individual chairs and desks, usually facing the blackboard where teachers have their tables nearby. Since 2003, every primary school child has received a free textbook which must be returned to the school at the end of the year to be reused by another child.

Mathematics lessons usually begin with the teacher speaking to the whole class, giving instructions about activities in the textbook. Students then complete the activities individually. Even in cases where children are seated in desks in pairs, or when there are no desks and they sit on the floor, students are working individually. Usually the teacher will call for silence as students 
Adelino Evaristo Murimo and Helen Forgasz

\begin{tabular}{|l|l|l|l|}
\hline \multirow{4}{*}{$\begin{array}{l}\text { Learner } \\
\text { variables }\end{array}$} & $\begin{array}{l}\text { Cognitive } \\
\text { development }\end{array}$ & $\begin{array}{l}\text { Spatial ability } \\
\text { Verbal ability }\end{array}$ & \\
\cline { 2 - 4 } & \multirow{2}{*}{ Beliefs } & $\begin{array}{l}\text { Confidence } \\
\text { Usefulness of mathematics } \\
\text { Sex-role congruency }\end{array}$ & \\
\cline { 2 - 4 } & Society & Motivation & $\begin{array}{l}\text { Fear of success } \\
\text { Attributional style } \\
\text { Learned helplessness } \\
\text { Mastery orientation } \\
\text { Performance following } \\
\text { failure }\end{array}$ \\
\cline { 2 - 4 } $\begin{array}{l}\text { Environmental } \\
\text { variables }\end{array}$ & Home & $\begin{array}{l}\text { Law, Media, Peers, } \\
\text { Cultural expectations }\end{array}$ & \\
\cline { 2 - 4 } & School & $\begin{array}{l}\text { Parents, Siblings, } \\
\text { Socioeconomic status }\end{array}$ & \\
\cline { 2 - 4 } & $\begin{array}{l}\text { Teachers, Organization, } \\
\text { Curriculum, Textbooks, } \\
\text { Assessment, Peers }\end{array}$ & \\
\hline
\end{tabular}

Table 1. Two categories of variables commonly used to explain gender differences in mathematics learning (adapted from Leder, 1990: 15).

work on the activities; any queries related to the activities are directed to the teacher. In Mozambican classrooms the value of competition in mathematics learning is emphasised more than cooperative work, and students with difficulties are usually ignored (Luís, 2004).

\section{Prior research}

\section{Gender issues and mathematics learning}

Gender equity in mathematics learning has been defined according to three dimensions: equity as equal opportunity to learn mathematics, equity as equal educational treatment, and equity as equal educational outcomes (Fennema, 1990). The dimension referred to as equal opportunity to learn mathematics, focuses on the equal right to participate in mathematics learning for both females and males. Equity as equal educational treatment is concerned with fair teaching in the mathematics classroom (and in textbooks), as females and males experience it through teacherstudent (and textbook-student) interactions. The third dimension, equity as equal educational outcomes, attempts to ensure that:

At the end of schooling, there should be no differences in what females and males have learned, nor should there be any gender differences in how students feel about themselves as learners of mathematics. Males and females should be equally willing to pursue mathematics-related careers and should be equally able to learn new mathematics as it is required (Fennema, 1990: 5).

The reasons for gender differences in mathematics learning are multifaceted and there are many explanations for them (for example, Leder, 1990; 1992; Leder, Forgasz \& Solar, 1996). Leder $(1990 ; 1992)$ reviewed research on gender differences in mathematics learning and identified the main variables commonly used to explain why, on average, females' achievement levels were lower than males', and why females were less likely to be enrolled in challenging mathematics courses - as summarised in Table 1 .

As shown in Table 1, gender differences in mathematics learning have been explained using two main categories of variables: learner-related and environmental variables. The learner-related variables are directly associated with the learner, while the environmental variables are external influences on the learner. Each category of variable is further divided into sub-categories. The learnerrelated variables are divided into cognitive development (spatial ability and verbal ability) and the personal beliefs. The internal belief system comprises a range of affective variables (Table 1) which were found to influence participation and achievement in mathematics, with males generally 


\begin{tabular}{|ll|}
\hline 1 & Equal numbers of males and females \\
2 & Males and females sharing active ('doer') and passive (helper/observer) roles \\
3 & $\begin{array}{l}\text { A balance of contextual settings of interest to males and females (not } \\
\text { necessarily gender-neutral activities) }\end{array}$ \\
4 & $\begin{array}{l}\text { The settings, occupations and professions illustrated or mentioned are not } \\
\text { gender-stereotyped }\end{array}$ \\
5 & The images of people and their names clearly reflect a multicultural profile
\end{tabular}

Table 2. A checklist for a gender-equitable mathematics textbook (adapted from Forgasz, 1996: 2).

holding more functional (likely to succeed) beliefs than females (Leder, 1990).

Leder's (ibid.) second category of variables comprised environmental variables which were divided into three subcategories: society, home and school (Table 1). Based on an extensive literature review, Koehler (1990) found that learning mathematics among males and females was strongly influenced by the educational environment including, for example, textbooks that were well known for their stereotyped remarks, sex bias, and the presentation of mathematics as a male domain (more suited to males than to females). In classrooms, teachers were found to spend more time with boys than with girls, with boys asking and being asked more questions than girls. Boys were also criticised and praised more often than girls.

\section{Textbooks, gender and mathematics learning}

Forgasz (1996) investigated gender equity in an Australian Mathematics textbook and produced a checklist of five equity issues (Table 2). It was claimed that in order to be considered gender equitable, textbooks and other educational materials needed to meet the five criteria (ibid.).

Appropriate depictions of females and males in mathematics textbooks are important because pictures and text that depict gender stereotyped roles and occupations and gender-biased language can send implicit messages to females and males that they incorporate into their understandings of life around them, and their place in it. Genderbiased text and images can contribute to or reinforce students' beliefs about gender role expectations. When the materials portray stereotyped images, students might develop inaccurate perceptions of their real potential and the potential of others (Stretmatter, 1994).

\section{Values of accessibility and 'specialism' in mathematics learning}

Bishop (1996: 19) defined values in mathematics education as "the deep affective qualities which education aims to foster through the school subject of Mathematics". According to Bishop (1988) and Bishop, Seah and Chin (2003), mathematics teachers promote three categories of values in classrooms: general educational, mathematical, and mathematics educational. General educational values do not have a mathematical component; however, teachers use a mathematical activity to discuss issues related to environmental protection or behaviour, for example. Mathematical values are related to the nature of mathematics itself, particularly the way mathematics knowledge was developed in different cultures over time. Mathematics educational values are related to the nature of teaching and learning Mathematics as a school subject. Although the three categories of values are important for research, the focus in the study reported here was only on mathematics educational values.

Seah (1999) characterised mathematics educational values in the following terms:

The norms and practices of doing mathematics as advocated by the mathematics teacher or textbook reflect values which are both mathematical and educational. Such values include encouraging or expecting pupils to display their workings of a problemsolving exercise in detail, as well as to double-check answers for accuracy before submission. (1999: 18)

According to Seah (ibid.), there are many categories of mathematics educational values to be found. However, in his study of textbook materials, Seah focused on five values that were most likely to be found in the classroom or in textbooks. These 
Adelino Evaristo Murimo and Helen Forgasz

\begin{tabular}{|l|l|}
\hline Values & Complementary Values \\
\hline Instrumental Understanding & Relational Understanding \\
Formalistic view of mathematics learning & Activist view of mathematics learning \\
'Specialism' & Accessibility \\
Theoretical & Relevance \\
Process & Product \\
\hline
\end{tabular}

Table 3. Mathematics educational values (adapted from Seah, 1999: 125-126).

values, and their complementary pairs, are listed in Table 3 .

As can be seen in Table 3, each mathematics educational value has a complementary value. Accessibility and 'specialism' were selected as the focus of the study reported here because they contain text features that can be analysed along gender lines. Text features of accessibility can convey embedded messages to students that everyone can find a place in mathematics learning (Bishop, 1988; Seah, 1999) rather than mathematics as a field for only a certain group of people (for example, males). Text features of 'specialism' convey the implicit message that in order to do well in mathematics, one needs to possess special knowledge and skills, such as appropriate vocabulary and formulae. In fact, accessibility is one of the principles that Bishop (1988) suggested for the development of an enculturation curriculum aimed at reaching all children:

Mathematics education should be for

all... the curriculum content must not be

beyond the intellectual capabilities of the children, nor must the material examples, situations, and phenomena-to-beexplained, be exclusive to any one group in society. (1988: 96)

According to Seah (1990), accessibility in mathematics learning is promoted in text materials when the following text features are evident: workers, labourers, females, and minorities are depicted using mathematical ideas in their daily life; students are invited to work collaboratively, and share information; the textbook writers convey concern by checking affective variables such as student confidence, attitude, and self-evaluation. 'Specialism' is the complement of accessibility, with text features including the following: mathematical concepts are presented with specialist vocabulary, often introduced through formal definitions; mathematics is presented as a product of gifted human actions (Seah, 1999).

The instruments used in this study to analyse the selected mathematics textbooks were developed out of the gender equity checklist suggested by Forgasz (1996) and the text features conveying accessibility and 'specialism' suggested by Seah (1999).

In the next section, a brief overview of the assumptions about the social world that informed the study is presented. Thereafter, the research methods used to select the textbooks, and the methods adopted to assess the validity and reliability of data will be discussed.

\section{Assumptions about the social world}

The study was informed by three paradigms, namely, positivism, interpretivism and constructionism, each of which reflects assumptions about the social world (Terre Blanche \& Durrheim, 1999).

Underpinning the positivist paradigm is the belief that there is an objective reality and that this reality can be accessed through observation that is directly experienced, measured, and verified by independent researchers. The aim of the positivist paradigm is to verify and describe in a rigorous way what people have already taken hold of or suspected (Terre Blanche \& Durrheim, 1999).

The interpretive point of view is concerned with the meanings that people attach to existent facts. In adopting an interpretive stance, the intention is to find out and describe how social phenomena are experienced by the people involved in those situations (Terre Blanche \& Durrheim, 1999).

The basis of the social constructionist paradigm is a belief that there are multiple and valid realities. Hence, constructionist researchers are interested in understanding how such realities, or 'human constructs', appear among a particular group of people. In other words, constructionism is interested in understanding how people determine what is normal and abnormal in particular contexts (Terre Blanche \& Durrheim, 1999).

Terre Blanche and Durrheim (1999) used a photograph in a magazine to illustrate how the positivist, interpretivist and constructionist paradigms have three quite distinct readings of the same scene. In this study the three paradigms were blended "because different paradigms exist 


\section{Depictions of females and males in Mozambican and Victorian (Australia) primary mathematics textbooks}

simultaneously, it is possible for the same researcher to draw on more than one paradigm, depending on the kind of work they are doing"' (Terre Blanche \& Durrheim, 1999: 7). The positivist position was of value to the study because it was important to know observable facts such as the number of females and males portrayed in the textbook materials. Likewise, the interpretive position was required to interpret the hidden messages that readers may gain from the textbooks, for example, it was important to discern whether mathematics might be portrayed as a 'male domain', 'female domain', or a 'domain for all, females and males'. The constructionist perspective was equally valuable because of sociopolitical differences between Mozambique and Australia, for example, culture, context, language, and curriculum.

\section{Methods}

\section{Selection of textbooks and grades}

Mozambican Primary Mathematics textbooks for the grades 6 and 7 were selected for analysis because they were recently issued in Mozambique and there has been no study of them. The analysis of gender issues in these textbooks was particularly important as gender differences in Primary education in Mozambique, as discussed earlier, are relatively large in these grades. Nelson Mathematics textbooks were selected in Victoria, Australia, because they were first introduced in the same year as the Mozambican textbooks (2003). Also, Nelson Mathematics is one of the most popular titles in Victoria. It should be noted that with respect to curriculum content, grades 6 and 7 in Mozambique correspond to years 5 and 6 in Victoria, respectively.

\section{Data collection, validity and reliability of data}

Content analysis is a non-reactive research method aimed at gathering and analysing the content of a text. The content of a text refers to words, meanings, pictures, symbols, ideas, themes, or any other explicit or implicit messages that can be communicated through a text (Neuman, 2003). In this study the four selected textbooks were thoroughly analysed page by page. In all pictures and drawings with gender-identifiable and countable people, the unit of analysis was a person. The number of pages in the textbooks varied between 100 and 120. The wording of every written problem was also analysed. The illustrated characters or photographed individuals and their actions were thus analysed and described in order to infer the implicit messages that they might convey to the reader. Crowded images, such as people in a train or market, and images showing only a small part of the human body (a hand, for example) were excluded from the analyses as it was difficult to identify their gender.

The validity and reliability of the subjective data collected were determined by recoding the same data from the texts over time (from January to June 2006). As the meanings of the visual material are culture-bound, the interpretation depends on the researchers' knowledge of the context (Neuman, 2003).

The instruments to collect data were validated by running a two-hour seminar involving mathematics and science students and lecturers at Monash University, Victoria, Australia. The participants represented different backgrounds. They were asked to identify the roles of the people illustrated in a number of randomly selected pages of the textbooks, and were asked to select, from a list provided, the values promoted by the textbook authors. During the seminar the selections were shared and discussion yielded three important outcomes that influenced the course of this study:

1) By comparing the findings obtained by the seminar participants with those of the firstnamed author of this article (undertaken a week earlier), the data gathering instruments were validated.

2) The data gathering instruments were improved by being able to describe more rigorously the features of people/characters portrayed in the textbooks that are engaged in active or passive roles.

3) Criteria were established to identify whether the textbook people/characters were mathematically cognitively engaged or not.

\section{Results}

The first question of the study sought to identify whether the photos and drawings illustrating females and males in the various textbooks were distributed with the same frequency throughout, in order to meet one of the criteria for gender equity put forward by Forgasz (1996). The numbers of females and males depicted, as well as the frequency ratio of females to males, are shown in Table 4.

As can be seen in Table 4, there were differences between the textbooks of Mozambique and Victoria in terms of the frequency ratios. The female to male ratios in the Mozambican textbooks were lower than 1.00:1 - indicating that males 


\begin{tabular}{|l|l|c|c|c|}
\hline Region & Level & Females & Males & F:M ratio \\
\hline \multirow{2}{*}{ Mozambique } & Grade 6 & 16 & 21 & $0.76: 1$ \\
& Grade 7 & 10 & 19 & $0.52: 1$ \\
\hline \multirow{2}{*}{ Victoria } & Year 5 & 20 & 20 & $1.00: 1$ \\
& Year 6 & 18 & 15 & $1.20: 1$ \\
\hline
\end{tabular}

Table 4. Distribution frequency of females and males in photos and drawings.

were illustrated more often than females. The Victorian year 5 textbook illustrated equal numbers of females and males, whereas the year 6 textbook illustrated more females than males. These results indicate that the Mozambican texts were more consistent with pattern of male and female depictions found in textbooks from earlier times in Australia in which more males than females were portrayed (Australian College of Education, 1977). In the textbooks of the mid-1980s in Victoria there was an attempt to portray females and males more equally, but it was found that there were still more males than females (Clarkson, 1993). The present study suggests that Victorian textbook writers and publishers seem to be responding positively to the need for gender inclusivity (Forgasz, 1996).

The second question of the study sought to determine how often females and males appeared together in the same photos or drawings. This question was important as the illustration of females and males in the same drawing could be used to reinforce gender-stereotypes, for example, by depicting males as the 'doers' and females as the 'helpers' or 'observers' (Forgasz, 1996). It was found that in the Victorian textbooks females and males were rarely illustrated together whereas in the Mozambican textbooks there was a trend to depict females and males together in about $27 \%$ of the images, with boys measuring and building, and girls standing, observing and playing.

The third question of the study was concerned with comparisons in the numbers of females and males in active roles (physical activities) and passive roles (non-physical activities). Forgasz (1996) associated active roles with doing something and passive roles with helping or observing. Based on these readings, active and passive roles were inferred from the actions undertaken by the characters illustrated in the textbooks. Table 5 presents a summary of the data (frequencies and female to male ratios) on the roles played by females and males.

The objective for the calculation of the female to male ratios in active and passive roles was to verify whether, as in the past, there were more males than females playing active roles and more females than males in passive roles (Australian College of Education, 1977; Clarkson, 1993; McKimmie, 2002).

As can be seen in Table 5 the female to male ratios for the Mozambican textbooks are lower than 1.00:1 in all categories. This means that more males than females were portrayed in active roles, as was also found in earlier times in Australia (Australian College of Education, 1977) and by Clarkson (1993). More males than females were also found in passive roles in Mozambican textbooks, which differs from past analyses (Australian College of Education, 1977; Clarkson, 1993; McKimmie, 2002).

The illustrations in the Victorian textbooks were more varied. Female to male ratios revealed that:

- Year 6 textbook: females and males shared equal numbers of passive roles (ratios of 1.00:1) and, in contrast with earlier textbooks (Australian College of Education, 1977; Clarkson, 1993), more girls than boys (ratio 1.60:1) were portrayed in active roles.

- Year 5 textbook: fewer females than males were depicted in active roles (ratio 0.77:1), and more females than males were portrayed in passive roles (ratio 1.43:1). The year 5 textbook

\begin{tabular}{|l|l|c|c|c|c|c|c|}
\hline \multirow{2}{*}{ Region } & \multicolumn{4}{|c}{ Active roles } & \multicolumn{3}{c|}{ Passive roles } \\
& & Females & Males & F:M ratio & Females & Males & F:M ratio \\
\hline \multirow{2}{*}{ Mozambique } & Grade 6 & 7 & 9 & $0.78: 1$ & 9 & 12 & $0.75: 1$ \\
& Grade 7 & 4 & 8 & $0.50: 1$ & 6 & 11 & $0.55: 1$ \\
\hline \multirow{2}{*}{ Victoria } & Year 5 & 10 & 13 & $0.77: 1$ & 10 & 7 & $1.43: 1$ \\
& Year 6 & 8 & 5 & $1.60: 1$ & 10 & 10 & $1.00: 1$ \\
\hline
\end{tabular}

Table 5. Distribution of active and passive roles between females and males. 

textbooks

depictions were consistent with earlier findings. (Australian College of Education, 1977, McKimmie, 2002)

Forgasz (1996) stated that a textbook reflects gender equity when females and males share equal passive and active roles. This was not always the case in the four textbooks, although the differences in numbers were not always great.

An attempt was also made to identify, through inference, whether females and males were equally mathematically engaged within their active and passive roles. In this study, to be mathematically cognitively engaged was defined as "thinking about mathematical concepts"; not mathematically cognitively engaged was defined as "thinking about something not mathematically-related" or "not thinking at all".

It was found that in the Mozambican textbooks, females and males were not equally mathematically cognitively engaged within their active and passive roles because in both cases, more males were depicted as mathematically cognitively engaged. This finding is consistent with earlier analyses of Victorian textbooks in which females and males were also not equally mathematically cognitively engaged in active and passive roles (Australian College of Education, 1977; Forgasz, 1996). However, in both active and passive roles there were slightly more females than males depicted as mathematically cognitively engaged in the Mozambican textbooks. This finding is consistent with earlier analyses in the Australian context (Clarkson, 1993; Forgasz, 1996; McKimmie, 2002) in which there was a trend towards depicting females in more positive roles, mathematically, than in earlier times. The present study has shown that the numbers of females have now surpassed that of males with respect to the depiction of mathematically cognitively active roles.

One of Forgasz' (1996) criteria for gender equity is that textbooks should present a balance of contextual settings of interest to males and females. While this criterion was not specifically examined in the present study, the genders of the people mentioned in the worded problems were categorised using 'manifest coding' (Neuman, 2003). Manifest coding refers to the coding of textual features such as the pronoun 'she' for a female, or the name 'Paul' for a male. All the words in the mathematical problems presented in the texts were analysed. It was found that in the Mozambican texts, males were mentioned twice as frequently as females. In contrast, in the Victorian texts, females and males were mentioned in equal numbers. An important difference between the Mozambican and the Victorian texts was the predominance of gender-neutral references in the Victorian texts. In contrast to Portuguese (the language used in Mozambique), many aspects of the English language are not gender-specific. In using English, the Victorian textbook writers have this characteristic available to them in their attempts to be gender inclusive.

The depictions of males and females in the textbooks from Mozambique more strongly reflected traditional, gender-stereotyped roles, with respect to mathematics learning, than did the Victorian textbooks. Whether conscious or unconscious, the message likely to be conveyed to students working with the Mozambican textbooks is that mathematics is a field of study more appropriate for males than for females - that mathematics is a male domain.

The penultimate research issue investigated in this study was to identify text features of accessibility and 'specialism' in mathematics learning and to examine them for gender differences. The use of specialist vocabulary, formulae, and the names or illustrations of male mathematicians were considered text features of specialism as they convey the message that mathematics is a product of gifted people, particularly those who understand the jargon and symbols involved, and is not for ordinary people (Seah, 1999). In contrast, when there were images and contexts depicting workers, labourers, women, and minorities applying mathematical concepts to solve problems in daily life, or when students were invited to pose problems, to work cooperatively and share information, and when affective variables such as attitudes, confidence and selfevaluation were verified, then the text features were considered to be valuing accessibility in mathematics learning, as they communicate implicit messages that every child can find a place in the mathematics learning process. Table 6 illustrates the number of times that females and males (and gender identifiable people) were depicted in the text features valuing specialism in the selected textbooks. 


\begin{tabular}{l|ccc|ccc|ccc|ccc|}
\hline & \multicolumn{4}{|c|}{ Mozambique } & \multicolumn{5}{c|}{ Victoria } \\
& \multicolumn{3}{|c|}{ Grade 6 } & \multicolumn{3}{c|}{ Grade 7 } & \multicolumn{4}{c|}{ Year 5 } & \multicolumn{3}{c|}{ Year 6 } \\
& F & M & GU & F & M & GU & F & M & GU & F & M & GU \\
\hline $\begin{array}{l}\text { Use of specialist vocabulary or a } \\
\text { formula }\end{array}$ & 9 & $\mathbf{2 7}$ & - & 13 & $\mathbf{2 2}$ & 1 & 6 & $\mathbf{7}$ & 9 & 11 & $\mathbf{9}$ & 13 \\
\hline $\begin{array}{l}\text { Mathematics knowledge: A } \\
\text { product of gifted human action }\end{array}$ & - & $\mathbf{2}$ & - & - & $\mathbf{1}$ & - & - & - & - & - & - & - \\
\hline
\end{tabular}

Table 6. Gender distribution among text features valuing 'specialism' in mathematics learning.

As can be seen in Table 6, in the Mozambican textbooks there were gender differences favouring males, as male names and faces were associated with mathematics specialist vocabulary two to three times as often as female names and faces. In the Victorian textbooks the gender differences in numbers were not great, due to the use of gender inclusive language; most of the problems and examples were often attached to people whose gender was unidentifiable. The Mozambican textbooks acknowledged the contributions to mathematics of three male mathematicians, two of whom were John Venn and Rene Descartes; the Victorian textbooks did not refer to any mathematicians.

Table 7 illustrates the number of times females and males were depicted in the text features valuing accessibility in mathematics learning in the selected textbooks. It is evident that the text materials in the two regions promote accessibility to mathematics learning to some extent. However, the aspects of the textbooks for which accessibility was promoted were culture-bound. Text features favouring accessibility in the Mozambican textbooks were demonstrated through the use of the local context, and mathematics was operationalised almost equally by females and males. There were thus no gender differences for this text feature, as females and males were almost equally portrayed using mathematics to solve their daily life problems.

The value of accessibility in mathematics learning in the Victorian textbooks was promoted through invitations to the reader to pose problems, to engage in collaborative work and information sharing, and through drawing attention to affective variables such as attitudes, confidence, and selfassessments. As shown in Table 7, there were no gender differences in the promotion of accessibility as the numbers of females and males were small, and there was a high proportion of gender neutral language as reported earlier in this paper.

With respect to the value of 'specialism', the results suggest that the messages conveyed in the Mozambican textbooks reinforce a perception that mathematics is an exclusive and specialised subject predominantly for males, while the Victorian textbooks imply that mathematics is a gender inclusive discipline. With respect to the complementary value of accessibility, the Mozambican textbooks convey the message that the mathematics of everyday situations is a gender inclusive

\begin{tabular}{|c|c|c|c|c|c|c|c|c|c|c|c|c|}
\hline & \multicolumn{6}{|c|}{ Mozambique } & \multicolumn{6}{|c|}{ Victoria } \\
\hline & \multicolumn{3}{|c|}{ Grade 6} & \multicolumn{3}{|c|}{ Grade 7} & \multicolumn{3}{|c|}{ Year 5} & \multicolumn{3}{|c|}{ Year 6} \\
\hline & $\mathrm{F}$ & $M$ & GU & $\mathrm{F}$ & $\mathrm{M}$ & GU & $F$ & $M$ & GU & $F$ & $M$ & GU \\
\hline $\begin{array}{l}\text { Context: workers, labourers, females } \\
\text { and minorities apply mathematical } \\
\text { ideas to solve daily life problems. }\end{array}$ & 17 & 13 & - & 5 & 4 & - & 1 & 2 & 1 & 1 & - & - \\
\hline $\begin{array}{l}\text { Students pose problems, work } \\
\text { cooperatively and share information }\end{array}$ & - & - & - & - & 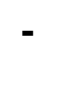 & - & - & - & 15 & 2 & 1 & 11 \\
\hline $\begin{array}{l}\text { Affective variables (attitude, } \\
\text { confidence, self-evaluation, etc) are } \\
\text { checked }\end{array}$ & - & - & - & - & - & - & 5 & 5 & 26 & 1 & 4 & 27 \\
\hline
\end{tabular}

Table 7. Gender distribution among text features valuing accessibility in mathematics learning. 

textbooks

activity. The Victorian textbooks focused on different aspects of accessibility, namely, its pedagogical and affective dimensions. Again, the Victorian textbooks were found to be gender inclusive due mainly to the use of the gender neutral aspects of the English language.

\section{Conclusions and recommendations}

Clarkson (1993), Forgasz (1996), and McKimmie (2002) reported improvements in the depictions of females in Victorian textbooks. This study has noted further improvements, although still not ideal. Forgasz' (1996) recommendations to ensure that mathematics textbooks are gender equitable were generally evident in the Victorian textbooks examined; however, further improvements are needed. For example, the textbook writers and publishers should ensure that males are not poorly depicted in attempts to depict females in more positive roles.

Not all the criteria suggested by Forgasz (1996) were examined in this study. Since Australia is a multicultural country, there is a need to investigate whether the characters illustrated, their names, and the contexts in which they are portrayed reflect the country's multicultural diversity.

While females were portrayed in the Mozambican textbooks, the content reflected what used to be the case with Australian textbooks in the 1970s (Australian College of Education, 1977), although there are small differences that are likely to be culturally based. These findings provide evidence of gender bias in favour of males, with images of males outnumbering those of females in photos and drawings. More males than females were also depicted in active (physical) roles, and as being mathematically cognitively engaged. Worded problems also mentioned more males than females. The mathematics educational value of 'specialism' was attached to male names and faces through the use of specialist vocabulary and formulae. Consequently, there is a risk that Mozambican children will perceive mathematics as an exclusive subject that is more appropriate for males than females. In portraying the mathematics education value of accessibility through everyday life contexts, this dimension of mathematics - also referred to as numeracy (Australian Association of Mathematics Teachers, 1998) - is likely to be seen as equally valuable for males and females.

Since Victorian textbooks generally reflected gender equity, there is much that the Mozambican Ministry of Education and Culture can learn, particularly as gender equity is now one of the education policy goals. To ensure gender equity in Mozambican textbooks something needs to be done urgently. Based on the findings of this study, it is recommended that the Mozambican Ministry of Education and Culture should elaborate guidelines on gender equity to orient the writers of textbooks and other instructional materials. The guidelines should also be available for teachers to align their classroom practices with gender equitable textbook materials.

It is acknowledged that the discussion of gender equity in mathematics textbooks does not, perhaps, answer all problems of gender differences in mathematics learning in Mozambique. However, the findings of this study are important because they open up discussion around gender issues in mathematics education in the country. Leder (1990) described many variables associated with gender differences in mathematics education. These variables should be investigated in the context of Mozambique and elsewhere in order to identify the contribution of each variable to the observed gender differences favouring males in educational outcomes. Certainly, one of the most important variables that requires urgent investigation in Mozambique is the influence of various cultural dimensions and economic issues on the educational outcomes of girls and boys in the context of high poverty rates faced by the majority of Mozambican families (UNICEF, 2006).

It is also important to bear in mind that previous research reviewed for this study was carried out in English, a language that has a gender neutral facility which, it was argued, made it easier for the Victorian textbook writers to be gender inclusive. This conclusion generates additional questions. What else may be hidden within the structure of various languages that is worthy of investigation? How do the students' mother languages (Bantu languages) affect the way in which they interpret gender issues portrayed in textbooks and other school materials?

The findings of this study cannot be generalised to other textbooks and regions. However, the general popularity of the textbooks in Mozambique and Victoria that were examined should not be disregarded.

Finally, the findings of this study are of significance. Mozambican textbook writers and publishers portrayed mathematics learning as a male domain whereas the Victorian textbook writers and publishers attempted to portray mathematics learning as a domain for all children, 
female and male. As gender equity in education is one of the goals in Mozambique advocated in educational policies, Mozambique should ensure that mathematics texts are not biased in favour of one particular group. Both females and males should be depicted positively in textbooks in order to support all children in reaching their full potential in mathematics learning.

\section{References}

Australian Association of Mathematics Teachers (AAMT). (1998). Policy on numeracy education in school. Occasional publication. Adelaide: AAMT.

Australian College of Education. (1977). Sex bias in mathematics texts. Tasmanian Chapter Newsletter (November 11), 31, 6.

Bernard, A. \& Cabral, Z. (2002). Gender and education in Mozambique: Analysis of results, lessons and recommendations. Retrieved January 12, 2006, from: http://www.unicef.org/ evaldatabase/index_18996.html

Bishop, A.J. (1988). Mathematical enculturation: A cultural perspective on mathematics education. Dordrecht, The Netherlands: Kluwer Academic Publishers.

Bishop, A.J. (1996). How should mathematics teaching in modern societies relate to cultural values? Some preliminary questions. Paper presented at the Seventh Southeast Asian Conference on Mathematics Education, Hanoi, Vietnam.

Bishop, A.J., Seah, W.T. \& Chin, C. (2003). Values in mathematics teaching - the hidden persuaders? In A.J. Bishop, M.A. Clements, C. Keitel, J. Kilpatrick \& F.K.S. Leung (Eds.), Second international handbook of mathematics education, Vol.2 (pp 717-765). Dordrecht, The Netherlands: Kluwer Academic Publishers.

Clarkson, P. (1993). Gender, ethnicity and textbooks. The Australian Mathematics Teacher, 49(2), 14-16.

Fennema, E. (1990). Justice, equity, and mathematics education. In E. Fennema \& G.C. Leder (Eds.), Mathematics and gender (pp 1-9). New York: Teachers College Press.

Forgasz, H. (1996). Equity and the selection of textbooks: An analysed example and a checklist. Vinculum, 33(4), 6-8.

Gerdes, P. (1988). On culture, geometrical thinking and mathematics education. In A.J. Bishop (Ed.), Mathematics education and culture (pp 137-162). Dordrecht, The Netherlands: Kluwer Academic Publishers.
Guz, A. (2000). Education for all: The year 2000 assessment report of Mozambique. Retrieved January, 20, 2006, from http://www2.unesco. org/wef/countryreports/mozambique/contents.ht $\mathrm{ml}$

Koehler, M.S. (1990). Classrooms, teachers, and gender differences in mathematics. In E. Fennema \& G.C. Leder (Eds.). Mathematics and gender (pp 128-148). New York: Teachers College Press.

Leder, G.C. (1990). Gender differences in mathematics: An overview. In E. Fennema \& G.C. Leder (Eds.), Mathematics and gender (pp 10-26). New York: Teachers College Press.

Leder, G.C. (1992). Mathematics and gender: Changing perspectives. In D.A. Grouws (Ed.), Handbook of research on mathematics teaching and learning (pp 597-622), New York: MacMillan.

Leder, G.C., Forgasz, H.J., \& Solar, C. (1996). Research and intervention programs in mathematics education: A gendered issue. In A. Bishop, K. Clements, C. Keitel, J. Kilpatrick, \& C. Laborde (Eds.), International handbook of mathematics education, Part 2 (pp 945-985). Dordrecht, Netherlands: Kluwer.

Luís, M.C. (2004). Por nim currículo de formação do professor de Matemática na perspectiva de construção do comhecimento. Unpublished Doctoral thesis, Pontifícia Universidade Católica de São Pauco (PUC), Brazil.

McKimmie, T. (2002). Gender in textbooks. Vinculum, 39 (4), 18-23.

Ministério de Educação e Cultura. (2003). Plano estratégico da educação. Mozambique. Retrieved January 11, 2006, from: http://www. mined.gov.mz/

Neuman, W.L. (2003). Social research methods: Quantitative and qualitative approaches (5th Ed.). Boston: Allyn \& Bacon.

Seah, W.T. (1999). The portrayal and relative emphasis of mathematical and mathematics educational values in Victoria and Singapore lower secondary mathematics textbooks. Unpublished Masters thesis, Monash University, Victoria, Australia.

Stretmatter, J. (1994). Towards gender equity in the classroom. Every teachers' beliefs and practices. USA: State University of New York Press. 
Depictions of females and males in Mozambican and Victorian (Australia) primary mathematics textbooks

Terre Blanche, M. \& Durrheim, K. (1999). Histories of the present: Social science research in context. In M. Terre Blanche \& K. Durrheim (Eds.). Research in practice: Applied methods for the social sciences (pp 1-16). Cape Town: Cape Town Press.
UNICEF (2006). Mozambique: The children primary school years. Retrieved January 11, 2006 from: http://www.unicef.org/mozambique /children_1594.html

"Research on gender and mathematics has provided a powerful scientific discourse during the past three decades.

The entire educational community - composed of practitioners, researchers, and policymakers - need to continue to engage in this discourse about and to explore ways to deepen our understanding of what equity is and how it can be achieved. It is in discourse about philosophical questions as well as research questions that our understanding of gender and mathematics will grow."

\section{Elizabeth Fennema}

